\title{
ANÁLISE BIOMECÂNICA DO CIMENTO CEMENT-POST POR MEIO DE ENSAIO MECÂNICO E DO MÉTODO DOS ELEMENTOS FINITOS
}

Ana Paula Gebert de Oliveira FRANCO, Diogo Henrique de BEM, Felipe Hecka de ALMEIDA, Mildred Ballin HECKE, Osnara Maria Mongruel GOMES

O objetivo desse estudo foi analisar o comportamento biomecânico de um cimento resinoso à compressão por meio do ensaio mecânico e do Método dos Elementos Finitos. Foram selecionados 20 pré-molares inferiores que foram submetidos à endodontia e à cimentação de pinos de fibra de vidro. Em seguida, as raízes foram seccionadas transversalmente, obtendo-se três discos de $3 \mathrm{~mm}$ de espessura. Os discos foram moldados e confeccionadas réplicas de resina epóxi, e os mesmos submetidos ao ensaio de compressão em uma máquina Shimadzu AG-I à velocidade de $1 \mathrm{~mm} / \mathrm{min}$ e carga de $220 \mathrm{~N}$. Após o ensaio mecânico, os discos foram novamente moldados e confeccionadas réplicas de resina epóxi. As réplicas foram observadas em microscopia eletrônica de varredura, onde foi selecionada uma imagem de um disco e transferida para o programa Auto-CAD 2007 para realização do modelo plano. Posteriormente, foi confeccionado o modelo tri-dimensional no programa ANSYS e simulado o mesmo ensaio. Os resultados sugeriram que o modelo computacional de adesão total apresentou uma distribuição de tensões adequadas, porém no corpo-de-prova real foi observada a presença de fendas previamente ao ensaio mecânico, o que dificultou a obtenção de adesão perfeita. Concluiu-se que a formação de fendas influenciou no comportamento do cimento. 